\title{
Filosofia, encontros, experiências: potência da pesquisa entre escola básica e universidade
}

Philosophy, meetings, experiences: potency of the research between elementar school and university

Andréa Scopel Piol Jair Miranda de Paiva

Resumo: O objetivo deste artigo é investigar movimentos transformadores de uma pesquisa produzidos no encontro entre universidade e escola básica, vividos com estudantes e docentes no cotidiano de duas escolas públicas de Ensino Médio de Aracruz, município do interior do Espírito Santo. A pesquisa buscou problematizar o ensino de filosofia na educação básica, em escolas de ensino médio daquele município. Como referencial teórico, destacamos a pesquisa pedagógica formativa, na concepção de Masschelein e Simons (2014), por nós tomada como força de invenção e afirmação criativa da própria existência. Do ponto de vista metodológico, nos inspiramos na cartografia de inspiração deleuzo-guattariana como acompanhamento de processos, na perspectiva de Barros-Kastrup (2012), bem como à ideia de Zeichner (1998) da necessidade de eliminar a separação entre o mundo dos professores da educação básica e o mundo dos professores acadêmicos. Como resultados, indicamos que o trajeto nos transformou, já não somos as pessoas do início, pois saímos transformadas dessa experiência. Concluímos que nós, professores e professoras, somos chamados a reinventar nossa prática, arriscar, abrir espaço para o pensamento, para novos fazeres, novas práticas. Temos pensado e inventado nossas práticas? Ocupamo-nos de nosso pensamento? O que ensinamos quando a proposta é ensinar a pensar? Como nós mesmos nos sentimos professores e professoras?

Palavras-chave: Filosofia. Pesquisa. Universidade. Escola. Transformação.

Abstract: The objective of this article is to investigate transformative movements of research produced in the encounter between university and basic school, lived with students and teachers in the daily life of two public high schools in Aracruz, a city in the interior of Espírito Santo. The research sought to problematize the teaching of philosophy in basic education, in high schools in that municipality. As a theoretical framework, we highlight educational training research, in the conception of Masschelein and Simons (2014), which we take as a force for invention and creative affirmation of our own existence. From a methodological point of view, we are inspired by Deleuzo-Guattarianinspired cartography as process monitoring, in the perspective of Barros-Kastrup (2012), as well as Zeichner's (1998) idea of the need to eliminate the separation between the world of teachers of basic education and the world of academic teachers. As a result, we indicate that the journey has transformed us, we are no longer the people of the beginning, because we left that experience transformed. We conclude that we, teachers, are called to reinvent our practice, take risks, open space for thinking, for new actions, new practices. Have we thought and invented our practices? Do we mind our thinking? What do we teach when the purpose is to teach how to think? How do we feel ourselves teachers?

Keywords: Philosophy. Search. University. School. Transformation. 


\section{Considerações iniciais}

Não há um modelo a imitar.

Há um mundo a ser criado. Um mundo novo.

O novo, ensina Deleuze, não se opõe ao velho, não é o futuro melhor perante o passado.

O novo opõe-se ao rotineiro, previsível, ordinário

(Walter Kohan. O que pode um professor?).

Este texto problematiza encontros entre escola básica e universidade pelo viés de uma concepção de pesquisa como transformação de si mesmo. Por um lado, recorremos à importância de se aproximar pesquisa, docência e possibilidade de dialogar com os sujeitos escolares, por outro, trazemos à baila nossa própria investigação ${ }^{1}$ como fio condutor de uma aproximação aos estudos pós-graduados como potencialização de um movimento que se encontra latente em tantos e tantos professores e professoras da educação básica. Nosso objetivo, assim, é discorrer sobre os movimentos de uma pesquisa produzidos na potência dos encontros entre sujeitos e pensamentos que nos provocam, afetam, deslocam nas linhas de forças pulsantes para pensar processos de vida, infância, currículo como experiências que emergem dos cotidianos de escolas.

Colocamo-nos numa perspectiva de pensar como uma pesquisa pedagógica formativa, no conceito de Masschelein e Simons (2014), que se constitui em um desejo de devir enquanto força da invenção, da afirmação criativa da própria existência, da transformação do eu. Devir enquanto afetos que se produzem nos encontros que se abrem à multiplicidade, ao pensamento, à mudança e às experiências.

Pensamos a pesquisa como um movimento de vida e criação, para além de exigência acadêmico-profissional, como acolhimento ao pensamento-criança, à experiência do encontro ${ }^{2}$ inventivo com outros corpos: experimentar encontros que os afetos tragam alegria e aumentem nossa potência de agir.

1 Este trabalho retoma e amplia ideias apresentadas no "Semfili - Seminário Internacional educação, filosofias, infâncias", ocorrido em São Mateus, ES, em agosto de 2018, bem como da Dissertação de Mestrado intitulada "Cartografias do Ensino de Filosofia no Ensino Médio: experiências em escolas públicas estaduais de Aracruz, ES", aprovada em dezembro de 2015, na UFES, São Mateus, Ceunes, no Programa de Pós-graduação em Ensino na Educação Básica. 2 Utilizamos o conceito de encontro de corpos em Espinosa que, para Deleuze (2002), está relacionado à produção de afectos. Podemos assim definir um ser pelo modo em que ele é 
Buscamos apresentar encontros vividos durante a pesquisa com estudantes e docentes no cotidiano de duas escolas públicas de Ensino Médio de Aracruz, município do interior do Espírito Santo, no ano de 2015, que teve como objetivo ensaiar uma cartografia de práticas de filosofia no ensino médio. Da mesma forma, enfatizamos como a potência da pesquisa como infância, recomeço, uma vez que a infância não é apenas uma questão cronológica, é uma condição da experiência, como nos mostra Kohan (2007).

Trata-se de uma pesquisa que deseja provocar um sentido transformador e inspirador, que implica condições ético-existenciais, o cuidado de si e a transformação do eu. Com uma relevância urgente e atual, é um convite para trabalhar consigo, alcançar um estado de atenção, de concentração nos próprios pensamentos e ações, uma entrega como uma condição de vida, um caminho para um novo começo. Esse cuidado de si implica uma relação consigo mesmo, com os demais e com o mundo em práticas que têm um efeito ativo, tempo e espaço para o cuidado e o "domínio do eu" (MASSCHELEIN \& SIMONS, 2014).

Com Larrosa (2002) pensamos a experiência como algo que nos toca ou que nos acontece e, ao nos deixar tocar por aquilo que nos afeta, nos transforma, constituindo-nos como sujeitos da experiência, isto é, abertos à sua própria mudança. Desse modo, o saber da experiência é o que se adquire no modo como vamos respondendo e dando sentido ao que nos acontece ao longo da vida. E, nessa pesquisa, buscamos cultivar a arte do encontro, a atenção e a delicadeza, escutar aos outros, conscientes de que buscar um sentido se faz com outros, em outros, para outros; possibilitando provocar novas experiências coletivas, transformadoras, com docentes e discentes.

Nesse contexto, este texto se liga à experiência de pensar com outros a partir de uma pesquisa entre escola básica e universidade. Assim, perguntamonos: qual a força do encontro entre escola básica e universidade? Que sentido uma pesquisa pedagógica pode assumir? O que ela pode implicar na vida do pesquisador? Tomamos tais questões como impulsos e potências afirmativas na

afetado por outro. Se os encontros forem alegres, potencializarão os corpos, se forem tristes, diminuirão a potência. 
produção de uma pesquisa, um convite para trabalhar o coletivo e nossa própria subjetividade, considerando a pesquisa como acontecimento.

$E$, no entrelaçar das experiências que têm afetado a minha ${ }^{3}$ vida, uma questão atravessa o que almejamos elaborar: é possível relatar uma experiência vivida? Há uma forma de dizer o que nos acontece, o que nos toca, o que nos transforma pela força de uma experiência atravessada? Como revelar a intimidade, a paixão, o entusiasmo, a alegria de uma pesquisa a partir dos encontros e dos afetos com os corpos?

As inquietações que movem esta escrita são forças, potências, sensações provocadas nos encontros e nas vivências de uma experiência de pesquisa realizada na escola pública durante o percurso do mestrado no Ceunes (Centro Universitário Norte do Espírito Santo) da Universidade Federal do Espírito Santo (UFES), nos anos de 2014-2015. Um acontecimento que me afetou com tamanha força tornando-me diferente, abrindo-me um espaço de experiências, mobilizando pensamentos, provocando afetos expansivos, que fez (e ainda faz) mudar meu pensar e meu viver.

Consideramos que o ponto de partida da pesquisa e do itinerário aqui narrado se encontrava em minha prática de professora numa escola de ensino médio de Aracruz, ES, a partir do que me afetou e me moveu à vontade de conhecer a universidade, a pesquisa. Movida por esse desejo, tomei-os como movimentos de vida ao entrar no Mestrado. Bons encontros com pessoas, conhecimentos, ideias, aprendizagens que foram invadindo com intensidade meus pensamentos, minha vida, fazendo sentido em mim. E, naquele momento, foram várias as circunstâncias que contribuíram para que eu pudesse sentir o prazer da pesquisa. Se, de um lado, exigiu de mim dedicação, atenção e abertura a ideias, autores, conceitos e questões, por outro, como diria Foucault (1998), esse processo me possibilitou passar por "uma experiência" como um trajeto no qual saí transformada; nesse sentido, atrevo-me a pensar que algo de vida se

\footnotetext{
${ }^{3}$ Em alguns trechos deste texto mantemos o pronome de $1^{a}$ pessoa tão somente para enfatizar a transformação pessoal da pesquisadora que tencionamos acentuar. No entanto, juntamente com nossos intercessores, sobretudo Deleuze-Guattari, acreditamos que somos um coletivo, multidão.
} 
passou entre mim e a educação, entre mim e a filosofia, como um devir que arrastasse ambas a caminhos inauditos.

A partir da educação básica e do encontro com a Universidade Pública, trilhamos um movimento cujo sentido foi a disponibilidade para abandonar a comodidade intelectual e existencial e uma abertura a pagar um preço determinado, como nos afirmam Masschelein e Simons (2014): "que tipo de preço nós estamos dispostos a pagar?". A pesquisa com sentido formativo, como produção dos conhecimentos científicos, como transformação de si ou a pesquisa pedagógica dominante?

Conforme Masschelein e Simons (2014, p. 70), a pesquisa pedagógica formativa é entendida como o trabalho sobre si próprio baseado no cuidado de si como "um exercício em que o eu põe em jogo a si mesmo e sofre uma transformação", pesquisa que busca um estado de atenção, pois pressupõe e, ao mesmo tempo, produz inspiração, curiosidade, gerando outras condições ético-existenciais e atenção para com a realidade educativa: "A questão é se estamos dispostos a pagar o preço de uma pesquisa pedagógica formativa, incorporada, inspirada e inspiradora, um preço que implica o cuidado e a transformação do pesquisador".

A pesquisa buscou problematizar o ensino de filosofia na educação básica, em escolas de ensino médio de Aracruz, interior do Espírito Santo. Tratava-se mais de uma preocupação do que uma pretensão por explicações ou acúmulo de conhecimentos; uma busca de significados e efeitos em mim e em outros. Assim, inspirada por alguns intercessores, optei traçar um caminho próprio: pensar algo que fizesse sentido em minha prática, uma vez que o ensino de filosofia que fazia parte da minha vida naquele momento e me incomodava. Desse modo, a partir dessa pesquisa, objetivamos, nesse texto, expressar os movimentos dessa experiência.

Em pesquisas há sempre encontros. Encontros entre sujeitos, movimentos, pensamentos, singularidades, virtualidades... Há possibilidades de bons e maus encontros, alegres ou tristes, afetos que podem aumentar ou diminuir nossa potência de agir, conforme Espinosa. A potência para agir aumenta ou diminui em virtude dos encontros, das conexões do corpo. "Tudo é 
apenas encontro no universo, bom ou mau encontro" (DELEUZE-PARNET, 1998, p. 73). Um bom encontro de corpo é aquele em que o corpo que mistura com o nosso combina com ele. Um mau encontro é aquele em que um corpo que se relaciona com o nosso não combina com ele e tende a se decompor nossa relação característica. Nesse sentido, quando há um encontro e a relação característica do corpo que nos afeta se combina com a relação característica do nosso corpo, nossa potência de agir aumenta. Quando temos um encontro no qual a relação característica do nosso corpo nos compromete, nossa potência de agir diminui (MACHADO, 2009).

Tomamos como referencial teórico-metodológico a cartografia em sua inspiração deleuzo-guattariana (DELEUZE-GUATTARI, 1995), que aponta para o acompanhamento de processos que se fazem a partir de forças, intensidades, movimentos, invenções, agenciamentos. Como estratégias de pesquisa, citamos a observação participante, entrevistas, redes de conversações e diário de campo, realizadas no ano de 2015. Consideramos a cartografia, segundo Barros-Kastrup (2012), como colocar-se à espreita do que se inventa no cotidiano escolar, em especial das linhas de fuga criadoras.

Estruturamos nosso texto em duas partes: primeiramente abordaremos a potência da pesquisa a partir de encontros vividos com estudantes e docentes, numa perspectiva de pesquisa que se mistura ao ambiente e com ele busca potências afirmativas da docência e da vida. Num segundo momento, relatamos experiências vividas e produzidas com professores no cotidiano de escolas públicas de Ensino Médio de Aracruz.

Na seção seguinte, relataremos uma experiência com os estudantes do Ensino Médio, assim como defender o ensino de filosofia como experimentação do pensamento na escola básica. Para isso criamos um espaço de desejo no cotidiano da escola pesquisada, um querer além da simples formalidade, que pudesse acenar para novas possibilidades de vida.

\section{Filosofia, encontros, experiências: o que dizem os estudantes?}

Estou no terceiro ano e não dou muita importância para a Filosofia hoje. Não é porque estou em um debate de Filosofia que vou mentir e falar que gosto. Hoje, na minha vida, eu dou 
importância para as matérias que vão levar a alguma coisa. E a filosofia só leva a gente a questionamentos do que é a vida para nos tornarmos talvez aquela pessoa melhor. Vou falar de várias pessoas que conheço lá na sala que fazem aula de filosofia por obrigação (Estudante do $3^{\circ}$ ano do Ensino Médio, 2015).

A filosofia deve causar um bom encontro. Entretanto, os maus encontros existem. Trazemos na epígrafe a fala de um estudante do $3^{\circ}$ ano do Ensino Médio em nossas redes de conversação 4 sobre filosofia na escola com os/as estudantes.

Devemos evitar o cultivo dos maus encontros de corpos ou ideias, das paixões tristes, e pensar no poder de afetar nossos estudantes do ensino médio. Pensamos, pois: o que a filosofia e seu ensino causaram na vida desse estudante? Qual o desejo de aprender filosofia? Ou, por que este estudante do terceiro ano não dá importância para a filosofia?

Se levarmos em consideração que é sempre um agenciamento que vai produzir enunciados, conforme Deleuze-Parnet (1998), logo, o enunciado é o produto de um agenciamento coletivo que põe em jogo os acontecimentos, as intensidades, os movimentos, os desejos, e nesse caso, os devires do ensino de filosofia no cotidiano escolar. "Na enunciação, na produção de enunciados, não há sujeito, mas sempre agentes coletivos; e daquilo de que o enunciado fala, não se encontrará objetos, mas estados maquínicos" (DELEUZE-PARNET, 1998, p. 85).

No caso desse aluno, percebemos que, apesar de reconhecer que o objetivo da filosofia é levar-nos a nos tornar "aquela pessoa melhor", reconhece que, no contexto atual, prefere as matérias "que vão levar a alguma coisa". Pensemos: que vão levar aonde? Ao mercado de trabalho, ao emprego, aos

\footnotetext{
${ }^{4}$ Conforme Ferraço e Carvalho (2012, p. 4-5), as redes de conversações expressam potência da concepção de currículo "[...] que criam novas formas de comunalidade expansiva, o que implica assumir a ideia de 'potência de ação coletiva', ou seja, da capacidade de indivíduos e grupos se colocarem em relação para produzirem e trocarem conhecimentos, gerando, então, o agenciamento de formas-forças comunitárias, com vistas a melhorar os processos de aprendizagem e criação nas coletividades locais, bem como no interior de redes cooperativas de todo tipo, ou seja, debater os 'possíveis' do currículo a partir dos conhecimentos, linguagens, afetos e afecções que estão em circulação nas práticas discursivas, em redes de conversações no cotidiano escolar". Nas escolas pesquisadas por nós, no primeiro semestre de 2015, tivemos encontros com alunos e docentes nos espaços escolares, grupos de conversa, entre outras estratégias citadas.
} 
concursos? Pensamos, também, que esse aluno percebe o convite que a filosofia faz à transformação de si, recuperando a tradição ética da filosofia como "forma de vida" e "prática de pensamento". No último período de produção de Foucault, o cuidado de si mostra a filosofia como forma de vida e transformação de cada um.

Pensamos com Deleuze-Parnet (1998, p. 75): "de que afetos você é capaz?". A força da pesquisa pode atingir a capacidade de afetar e ser afetados? O que experimentamos com os estudantes? "Experimente, mas é preciso muita prudência para experimentar".

Assim, entre sujeitos e, roubando de Deleuze: entre-tempos, entremomentos, entre vidas de estudantes em duas escolas de Ensino Médio de Aracruz, ES, para pensar as singularidades, os acontecimentos constitutivos e produzidos no ensino de filosofia, ousamos inventar um grupo de conversação com os estudantes do Ensino Médio para pensar a Filosofia, assim como desenvolver experiência de pensar com outros. Mas, o que essa experiência nos/me toca? O que nos/me afeta?

Este estudante revela sua insatisfação, seu descontentamento com a filosofia, com seu ensino, sua aprendizagem, com as aulas. Afirma fazer a disciplina por obrigação, porque não vê sentido, não vê significado, não gosta da filosofia e das coisas que são ensinadas, pelas quais não se interessa. Nesse sentido, afirma: "na escola, eu dou importância para as outras matérias". A expressão comove, impressiona. Pensamos: este estudante já está no terceiro ano do Ensino Médio e ainda não foi tocado pela filosofia, pelo seu ensino, pelo conhecimento, pela experiência de pensamento. Poderíamos perguntar: por que, então, se sentiu tocado para participar das redes de conversações sobre filosofia? Revelou a importância de ser verdadeiro em seu questionamento, afirmando que não podia omitir ou dizer o contrário. Afinal, por que ele teria que gostar de filosofia?

O grupo foi ficando preocupado com a presença do estudante, com algumas indagações que foram causando cada vez mais discussões, problematizações e novos pensamentos. Para nossa surpresa, em nosso último encontro, esse estudante relata: 
Talvez, mesmo com um conceito diferente dos demais da turma em relação à filosofia, consegui criar um pensamento diferente. Sendo a primeira aula que realmente consegui entender a importância da filosofia e o que ela tenta fazer na vida das pessoas. Coisas que nunca havia sido tocado, ensinado, coisas que nunca havia acontecido comigo em todas as aulas de filosofia. Obrigado!

Com essas aulas, podemos dizer que a flecha atingiu seu alvo. E lembramos de Deleuze (1994, p. 52): "uma aula quer dizer momentos de inspiração, senão não quer dizer nada". São ensaios, espaços e temporalidades especiais nos quais muitas coisas acontecem. É algo que se estende de uma semana a outra, às vezes por vários meses.

$E$, se levarmos em consideração que o nosso público é fascinante como nos revela Deleuze, diante dos estudantes tomados como sujeitos especiais que levem a momentos de inspirações, perguntamo-nos: como nos preparamos para uma aula? Como nos preparamos para esses momentos de inspiração com nossos estudantes? Será que fazemos o possível em nossas salas de aula para chegarmos ao ponto de fazer algo com entusiasmo ou provocar entusiasmo aos nossos adolescentes do ensino médio?

Sabemos que nem sempre é fácil dar uma aula com entusiasmo ou até mesmo provocar entusiasmo nas salas de aulas nos dias atuais, sobretudo nas condições de trabalho de muitos (as) docentes da educação básica. Contudo, para Deleuze (1994, p. 52), o ensaio e a inspiração fazem parte do nosso papel do professor. Isso nos faz pensar que uma aula é algo preparado para vivenciar momentos de inspiração. Há uma sequência, um desenvolvimento interior numa aula em que "não podemos recuperar o que não conseguimos fazer":

Uma aula é uma espécie de matéria em movimento. É por isso que é musical. Numa aula cada grupo ou cada estudante pega o que lhe convém. Uma aula ruim é a que não convém a ninguém. Não podemos dizer que tudo convém a todos [...]. Uma aula é emoção. É tanto emoção quanto inteligência. Sem emoção, não há nada, não há interesse algum. Não é uma questão de entender e ouvir tudo, mas de acordar em tempo de captar o que the convém pessoalmente (DELEUZE, 1994, p. 56).

Na sequência, vejamos alguns relatos de estudantes das três séries do Ensino Médio, produzidos nas redes de conversações. O que esses 
adolescentes pensam e relataram de suas aulas de filosofia e, consequentemente, de seus professores?

\section{Aula como momentos de questionamentos}

Estudante 01: Eu acho que os debates são as melhores aulas que a gente tem. Não adianta passar determinada atividade pra gente. Aí a gente fica lá fazendo e nem sabe o que tá fazendo na verdade, só faz porque tem que fazer, não tem? Faz e entrega lá. Eu acho muito mais interessante pegar um tema, reunir a sala e debater, como a professora faz com a gente de vez em quando. É bem mais legal do que a gente pegar aquela folha desse tamanho e ficar lá pesquisando horas e horas no livro.

Estudante 02: Depende muito da forma que a aula é dada, pois de maneira certa ela faz questionar por algum instante. A aula teve grande diferença na minha vida. Hoje sou esquerdista, que se preocupa com o todo e não com a parte.

Estudante 03: As aulas são produtivas, porque em boa parte do tempo o que é apresentado ajuda a desenvolver outras áreas, no sentido de trazer mais questionamentos e mais porquês para a nossa vida, principalmente quando há debates que eu gosto muito.

Estudante 04: Nossa professora desse ano não só conta a história e fala é isso, ela é meio que se questiona, vai fazendo a gente pensar [...]. Mas já tivemos muita dificuldade antes, no primeiro ano.

Estudante 05: Eu já mudei algumas coisas do meu pensamento. $E$, a Filosofia ensina a sermos de certa forma livres. $E$ as aulas tem que fazer isso mesmo, fazer a gente pensar.

Estudante 06: Se toda a matéria de filosofia fosse dada em forma de debates como esse, eu acho que os alunos se interessariam ainda mais, entendeu? Por que eles se questionariam e procurariam buscar mais conhecimento sobre o assunto.

Diante dos conceitos desses estudantes, podemos tecer alguns apontamentos e levantar outros questionamentos:

Defendem os momentos de questionamentos e de debates em sala de aula como os mais interessantes. Esses estudantes demonstram expectativas de uma boa metodologia para o ensino de filosofia. Quando o aluno nos revela: "depende muito da forma que a aula é dada, pois de maneira certa ela faz questionar por algum instante", somos levados a nos perguntar: o que esse aluno 
quer nos revelar quanto à metodologia de uma aula? Certamente, uma aula que não faz pensar não vai fazer sentido para ele;

Podemos perceber nessas falas que há aulas que nãos lhe convêm: "Às vezes eu acho que não adiante passar determinada atividade pra gente. Aí a gente fica lá fazendo e nem sabe o que tá fazendo na verdade, só faz porque tem que fazer". Pensamos com Deleuze, sem emoção não há aula. Daí há necessidade de denunciar a estrutura arbórea das aulas e fazer brotar a grama, preencher os vazios do ensino de filosofia, fugir dessa estrutura de ensino e fazer rizomas. Impõe-se com urgência um ensino de filosofia como uma radical atitude crítica e não um "almanaque de repetição". É preciso um movimento de desterritorialização e reterritorialização de nossas metodologias, didáticas; perder-se para se encontrar;

Se tomarmos o foco de que as aulas de filosofia "têm que fazer a gente pensar", podemos considerar que essa perspectiva vai ao encontro do que Kohan (2000) e Gallo (2006) propõem ao ensino de filosofia: propiciar espaços de pensamentos livres e abertos. Fazer da aula algo transformador.

Vejamos, a seguir, trecho de outro diálogo com alunos sobre suas experiências com as aulas de filosofia.

\section{Aula baseada em conteúdos}

Estudante 01: Então, o que o professor do ano passado e outros faziam nas aulas: enchia o quadro de texto, dava uma prova com mais textos e mandava sempre a gente interpretar, ou seja, coisa que a gente já faz em português, porque é muito bom fazer interpretação de textos, mas, é uma aula chata e fica mais chata.

Estudante 02: A Filosofia não ensina a questionar? Como é que eles querem que a gente fica dando respostas para as perguntas do livro, se a filosofia ensina a questionar e não a aceitar aquela verdade ali?

Estudante 03: [...] Antes a gente se perdia muito copiando um texto dos filósofos gregos. Era horrível. Era diferente, a gente nunca debatia em grupo, né? Pra ser sincera, eu me interessei mais em estudar Filosofia esse ano porque a professora trouxe uma forma mais descontraída.

Estudante 04: É necessário um professor meio que fazer a gente decorar um monte de coisas, nome de filósofos, datas, anos? Nossa! Sinistro isso. A importância de Sócrates, e de não sei 
quem, é muita coisa, eu acho que isso daí pra mim não é necessário.

Estudante 05: Que nem essa professora agora, pra mim está sendo bom demais, melhorou muito as dinâmicas. A professora do ano passado só sabia passar matéria e mais matéria, explicava um pouco e passava mais. Na hora de pegar na prova a gente não entendia o que ela estava querendo.

É curioso observar, em alguns momentos, como essas falas revelam um desencontro, um mau encontro entre as perspectivas dos/das alunos/alunas e a prática do professor, entre a filosofia e o seu ensino nos cotidianos escolares. Por um lado, discentes relatam aulas "conteudistas" que já tiveram como aquelas nas quais os professores ou professoras enchem o quadro de conteúdo, sem momentos para pensar, conversar, problematizar, produzir, em suma: um ensino insignificante, tradicional; por outro, as perspectivas de uma aula que faz pensar, questionar e provocar o pensamento.

Por fim, vejamos como os/as estudantes se questionam sobre suas aulas, mesmo quando são propostas dinâmicas, debates, se perguntando: o que há de filosófico nisso?

\section{Aula como dinâmicas}

Estudante 01: Eu gosto porque a professora dá dinâmicas nas aulas, manda a gente falar a nossa opinião.

Estudante 02: Eu não gosto de dinâmicas. Todas as aulas dinâmicas! Isso é filosofia? Será que não tem alguma coisa para argumentar, pensar entre a gente.

Estudante 03: De uma forma bem coloquial, o ano passado era chata e tediante (sic) porque você copiava muito, falava de pessoas que você nunca conheceu e nunca vai querer saber [...]. Já a professora desse ano melhorou muito as aulas. Trouxe dinâmicas.

Estudante 04: Não tem como não interagir nas aulas de filosofia porque, além das dinâmicas, têm várias brincadeiras que chama atenção.

Estudante 05: Fomos para quadra, lemos um texto sobre o amor e a professora falou de vários tipos de amor.

Estudante 06: Eu não vejo nada nessas aulas de dinâmica. A professora poderia intercalar com o conteúdo, uns assuntos sobre filosofia. Ficar assim: dinâmicas, filmes e falar o que achou 
só. Eu não gosto dessas atividades. A gente faz filosofia por obrigação.

O curioso é observar as potencialidades que existem nos discursos dos alunos, assim como as fragilidades existentes no ensino e na aprendizagem de filosofia. Nesse espaço de complexidade, incertezas e possibilidades do cotidiano escolar os dados vão se vislumbrando e ora nos surpreende, ora nos afeta pelo seu elemento problemático.

Se ensinar filosofia é "dar lugar ao pensamento do outro", é aceitar que se trata de uma questão de experimentar o pensamento, perguntamo-nos, então: estamos afirmando, em nossas aulas de filosofia, uma política de pensamento em busca do movimento de criação, como nossos intercessores Kohan-Gallo nos propõem? O que essas assertivas nos fazem pensar em relação a seu ensino? Imaginamos, então, o encontro entre filosofia e seu ensino, um bom ou um mau encontro. Nesses depoimentos, apontamos a tensão existente entre, de um lado, as dificuldades de propiciar práticas ativas, criativas e significativas e, de outro lado, o reconhecimento de que, nas escolas públicas de ensino médio de Aracruz, existem docentes que engendram práticas significantes. Se, de um lado, alguns depoimentos causam estranheza, por outro, podemos levantar a possibilidade de haver também ensino criativo em tais situações, aproximando a noção de filosofia como experimentação.

Pensamos, então, se uma aula é emoção e sem emoção não há nada, o que fazemos então, quando em uma aula não conseguimos chamar atenção de nossos alunos, quando não conseguimos sensibilizá-los para o assunto? Não estaríamos dando uma aula? E a questão se torna: como propor aos alunos do Ensino Médio um ensino ativo, vivo e criativo que propicie experiências de transformadoras de si?

Pensamos com Gallo (2012) que a aula de filosofia pode ganhar sentido interessante ao ser tomada com o uso de recursos artísticos: uma imagem, um filme, uma música, um poema, um conto, uma história em quadrinhos, um desenho animado, programas de televisão ou peças artísticas, etc.

Vejamos a produção de uma conversa com estudantes do ensino médio no grupo de conversação: 
Aluno 07: Nossa professora desse ano não só conta a história e fala é isso, ela é meio que se questiona e que questiona a gente [...]. Ela vai fazendo a gente pensar e não só ficar ouvindo. Mas já tivemos muitas dificuldades nos outros anos.

Pesquisador: Quais dificuldades tiveram nos anos anteriores?

Aluno 06: O professor de filosofia que eu tive no primeiro ano, o método de ensino dele era diferente. Ele não era nada didático. Ele copiava muito no quadro, muita escrita, muito mesmo. Depois, fazia a gente ler aquilo, explicava e pronto. E ninguém entendia nada.

Aluno 07: Eu, no primeiro ano, não gostava de Filosofia.

Aluno 06: Ele tentava fazer o método da faculdade, entende?

Pesquisador: Não, como assim, o método da faculdade?

Aluno 06: É que ele dava aula também na faculdade. Aí, ele usava o método com a gente que ele usava na faculdade. E pra gente que tinha acabado de chegar ao primeiro ano não funcionou. Era muito difícil.

Pesquisador: Mas, como acontecia? Vocês não utilizavam o livro didático?

Aluno 06: Às vezes, mas o livro didático também não tinha nada de didático, era bem rebuscado pra gente que nunca estudou filosofia. Ele passava a matéria no quadro e explicava, mas ficava de uma forma difícil. Então, eu já tive três professores de filosofia: esse que usava o método da faculdade, que não era nada didático, copiava demais no quadro e depois explicava o conteúdo e ninguém entendia nada porque era difícil. $\mathrm{O}$ outro professor que eu tive era bem mais didático, só que mesmo assim não era bom. Ele ficava muito parado, não fazia discussão com a gente, nem problematização. Já a professora que estamos estudando agora, ela faz a aula ficar bem melhor. Ela faz a gente pensar e questionar bastante.

Pesquisador: Então, atualmente, as aulas de filosofia são melhores?

Aluno 06: sim, mas depende muito. Se quem está no primeiro ano pegar um professor que ensina aquele método da faculdade, o aluno daqui não vai entender nada. Eu, atualmente, gosto mais de filosofia. Porque a professora agora não só conta história, mas dá liberdade, ela nos faz parar para pensar.

Aluno 07: O interessante é que algumas vezes somos puxados para dentro do assunto. $E$ a partir do momento que você fala sua opinião você é questionado, e isso abre sua mente ainda mais para os problemas sociais. As perguntas nos pegam de surpresa. Ela faz isso com a gente, mas no primeiro foi horrível, matéria, matéria, matéria e ninguém entendia nada. No segundo 
ano não era assim tão bom também, acho que a aula não era muito aproveitada. Sabe, quando enrola um pouco?E também, um assunto sem sentido para a vida. Sabe, um bom professor faz muita diferença.

Estamos diante de um panorama complexo, no qual o ensino de filosofia se apresenta em duas dimensões: temos, por um lado, uma dimensão objetiva que talvez se esgote na simples repetição de ensino tradicional. De fato, um professor preso ao ensino enciclopédico, baseado em informações sobre a história da filosofia, corre o risco de impedir o exercício da filosofia como experiência de pensamento (GALLO, 2006; 2012; KOHAN, 2000, 2009), levando ao seu desprezo. Por outro lado, temos um professor que provoca 0 pensamento, instiga, faz pensar, produz diferenças.

O desafio de todo docente, em especial, de quem ensina filosofia é conseguir em suas aulas ir além da transmissão de informações, da simples repetição e explicação. Ensinar filosofia não significa apenas transmitir os saberes da história. Deveríamos fazer da aula de filosofia um ato de experimentação, criação e recriação, um pensar compartilhado, como nos sugerem nossos intercessores.

Certamente, o ensino de filosofia traz implicações desafiadoras aos docentes que ensinam filosofia no Ensino Médio e à formação inicial e continuada. Não é tão fácil quando estamos nas salas de aula. No contexto das aulas de filosofia que vivenciamos em nossa pesquisa de campo, pudemos perceber um agir diferente de lógicas, sujeitos, pensamentos, um modo específico de ensinar filosofia em cada cotidiano dessas escolas. Cada cotidiano escolar tem sua própria especificidade que precisa ser investigado para que o ensino seja ligado às vidas dos alunos, sem perder o rigor (como eles dizem: 'sabe quando enrola um pouco?'), e a análise filosófica.

A seguir, veremos como se podem dar encontros de pesquisa numa escola e sua potência de transformação na vida de quem pesquisa.

\section{Encontros alegres: experiências com professores e o ensino de filosofia}

Que experiências podemos relatar dos encontros com os professores pela pesquisa? Quais foram os afetos produzidos com as professoras das escolas 
pesquisadas? As experiências coletivas que serão aqui narradas são resultados dos agenciamentos dos corpos, da simpatia, dos afetos, do desejo, do encontro de uma boa relação com os participantes da pesquisa.

Entre as escolas e os participantes podemos trazer alguns elementos importantes, uma vez que consideramos que é nos cotidianos que os "sujeitos encarnados lutam, sofrem, são explorados, subalternizados, resistem, usam astúcias para se defender das estratégias e dos poderosos, se organizam para sobreviver, e assim vivem, lutam, sobrevivem [...]" (GARCIA, 2003, p. 195). Nesse sentido, valorizamos o lócus de produção dessa pesquisa não meramente como um campo estranho de pesquisa, mas, como nossa vida mesma em análise.

É interessante a experiência de produzir dados não apenas com os professores de filosofia e estudantes, mas, também, com os diretores das escolas, pedagogos, coordenadores, secretárias e demais professores. Em cada escola que estivemos, destacamos a força das conversas com os professores e professoras de filosofias. É surpreendente estar entre eles e como uma pesquisa os provoca, os mobiliza: querem falar, buscar....

O que poderíamos dizer, então, da acolhida no campo de pesquisa? Construir algo que nos afeta é prazeroso e ao mesmo tempo provoca curiosidade, a chegada às escolas, a recepção pelos sujeitos, seja um porteiro, uma secretaria, uma diretora... E depois, professores e estudantes. Não apenas tivemos o privilégio de estar entre professores de filosofia e estudantes, mas de demais profissionais da educação. É curioso o modo como somos recebidos em cada escola e por cada pessoa; há esperança de que estamos ali para fazer algo melhor para a escola. Assim disse o diretor de uma escola: "A escola é nossa e está de portas abertas para a pesquisa. Precisamos disso: do novo, do diferente, de alguém para se misturar com os professores e pensar o ensino. Pode conversar com as pedagogas, os professores, estar nas salas de aula e fazer suas atividades. Fica à vontade". Conforme anotações no diário cartográfico, uma professora fala da importância que vê na pesquisa para os professores de filosofia, no sentido que o sistema educativo, o órgão responsável, possa nos oferecer meios para a melhoria do ensino, levando em consideração que muitos 
docentes que atuam no ensino de filosofia não têm habilitação específica e, também, não há uma formação continuada específica para esse ensino. Nesse sentido, a professora relata: "Que essa pesquisa chegue às autoridades e por elas seja pensada, a fim de contribuir com o professorado dessa área". Um professor destaca em seu questionário: "Parabenizo a prezada mestranda pela importante pesquisa na área da filosofia. Pois são iniciativas como essa que possibilitam o melhoramento e a reflexão acerca do papel e da qualidade da educação prestada em nosso município". Outro professor, se referindo à disciplina filosofia, diz uma simples frase: "Filosofia? Coisa que ninguém vem pensar!".

São situações que causaram afetos alegres e, logo, um feliz encontro. Pudemos compreender, a partir desses sujeitos que produzem enunciados, suas perspectivas quanto ao ensino de filosofia no cotidiano das escolas. Perspectivas, talvez, para além dos resultados da pesquisa acadêmica, como nos sugere Zeichner (1998), implicando-nos intimamente e nos levando a agir no sentido de contribuir com o fazer docente.

Quando um professor, referindo-se ao ensino de filosofia na escola, nos diz: "Filosofia? Coisa que ninguém vem pensar!", pensamos no distanciamento entre a Escola Básica e Universidade e a necessidade de uma aproximação: "Apesar de a academia não reconhecer a importância de deliberar juntamente com professores sobre o significado de seu trabalho, alguns pesquisadores universitários estão tentando fazer isso [...]" (ZEICHNER, 1998, p. 3).

Zeichner (1998) discute a tensão entre pesquisadores acadêmicos e professores na pesquisa educacional e a necessidade de eliminar a separação entre o mundo dos professores e o mundo dos professores acadêmicos. Aponta resultados de pesquisas conduzidas por acadêmicos em escolas que envolvem ativamente os professores e a significação das pesquisas para suas práticas. "Alguns pesquisadores universitários estão começando a sentir uma obrigação ética de se engajar nesse diálogo" com o objetivo de romper, ultrapassar a linha divisória entre pesquisadores acadêmicos e professores da escola básica. Precisamos, pois, ter "honestidade no relacionamento com aqueles que abrem suas vidas para os pesquisadores acadêmicos", que são, especialmente, 
participantes e coautores da pesquisa, como nos sugerem os pesquisadores dos e com os cotidianos.

Nesse sentido, as redes cotidianas dessa pesquisa envolvem diferentes sujeitos que praticam a realidade nas escolas, de acordo com a incisiva expressão de Certeau (1994). Destacamos, então, como sujeitos da pesquisa com o cotidiano "[...] todos aqueles que, de modo mais visível ou mais sutil, deixam suas marcas nesse cotidiano, isto é, os sujeitos das pesquisas com o cotidiano são: alunos, professoras, mães, vigias, serventes e tantos outros que 'vivem' as escolas” (FERRAÇO, 2007, p. 74, grifos do autor).

Queremos destacar, também, a necessidade que o professor tem de dizer o que pensa, de dizer o que faz e o que ensina em sua sala de aula, as suas dificuldades e as dos alunos; demonstrando, ao mesmo tempo, a alegria da presença de alguém para ouvi-lo. Uma professora muito disposta nos chama a atenção em seus dizeres e gestos. A professora, primeiramente, se mostra feliz com a oportunidade de poder participar da pesquisa, de falar, de dizer suas necessidades, experiências e práticas.

Assim, narramos uma experiência vivenciada ${ }^{5}$ : na sala dos professores, a professora de filosofia senta em uma cadeira e convida a pesquisadora para sentar. Sem nenhuma pergunta, a professora começa a dizer como ensina filosofia para seus alunos do ensino médio. Nesse momento, se levanta e pega várias atividades em seu armário, mostrando e dizendo os objetivos que pretende alcançar com o uso dessas atividades que foram por ela produzidas, criadas. A professora revela que nos livros didáticos há uma ausência de atividades atraentes e prazerosas para o ensino e a aprendizagem de filosofia, portanto, inventa algumas. São atividades interessantes, relacionando imagens e linguagem escrita. Outras privilegiam charges, interpretação de imagens e criatividade no ato de formar textos. Mas, num gesto de preocupação, vai ao seu armário novamente e traz atividades realizadas no processo de aprender e ensinar filosofia, mostrando e explicando cada uma delas. Em seguida, fala um pouco sobre o livro didático adotado pela escola: Iniciação à filosofia, de Marilena

\footnotetext{
${ }^{5}$ Essa narração está descrita num estilo coloquial para manter a autenticidade do momento com a professora e o registro no diário de campo.
} 
Chauí, os conteúdos, as suas dificuldades e as dos alunos, esclarecendo que tenta propor atividades que não levem ao desprezo pela filosofia. Por último, diz que vai fazer o questionário em casa, pedindo para o pesquisador retornar no dia do seu planejamento. Demonstra interesse e disponibilidade para participar de uma entrevista, se for preciso. Pensamos: o que podemos considerar a partir desse relato? O que essa professora quer nos revelar? Quais suas necessidades? O que agenciar?

Pensamos que se trata de nos abrir para conexões e agenciamentos. Cabe destacar a importância do ato de "contar", de "partilhar", de "agenciar" as nossas dúvidas, as nossas dificuldades, as nossas potencialidades, as nossas invenções, as nossas experiências, as nossas hesitações como profissionais docentes. Aqui a pesquisadora é também docente, pois esse é seu impulso inicial, como anteriormente mencionado.

A partir de questionários com todos os professores de filosofia das escolas estaduais de Aracruz, de entrevistas semiestruturadas com duas professoras e redes de conversações com estudantes de escolas diferentes, pudemos reconhecer nesses momentos, nesses encontros com os professores e alunos, a potência dos discursos narrados e do acolhimento do elemento problemático: o ensino de filosofia e as implicações do campo da formação docente, que abordaremos a seguir.

Numa combinação de pesquisa cartografia e pesquisa com o cotidiano em escolas de ensino médio de Aracruz, podemos afirmar que nessa participação inúmeros elementos salientes despontaram, deslocando a atenção do foco problemático por elementos de dispersão que eram produzidos no cotidiano das escolas: os intervalos das aulas, a "indisciplina" nas salas de aula, os planejamentos dos professores, as conversações nas salas dos professores, os inúmeros imprevistos que acontecem no cotidiano escolar. Usando as palavras de Barros e Kastrup (2012), nos aproximamos do campo como estrangeiros visitantes de um território que foi sendo explorado por cenas, discursos, olhares, escutas, gestos, ritmos e afetos.

Quando iniciamos a pesquisa, não sabíamos, de fato, o exato caminho que iria ser percorrido e como tudo iria acontecer ou se proceder. Até nos passa 
um pensamento de encontro com os participantes da pesquisa, as entrevistas, a produção de dados e tudo concluído. Mas, nada disso! Nos encontros com professores e professoras criamos vínculos, afetos e afecções que não se fecharam, pelo contrário, a experiência provocou novas aberturas e não o fim.

Em um dia qualquer, era mês de Agosto (2015) e já havíamos terminado a produção do questionário de pesquisa nas escolas de Aracruz, recebi ${ }^{6}$ um telefonema de uma professora de filosofia que participou do questionário produzido entre Março e Maio. E logo pergunta: quando você vai voltar? Eu gostaria de conversar com você. Imediatamente, pensei: O que está acontecendo? O que essa professora está querendo comigo? Por um lado, senti uma grande emoção, felicidade, a alegria de ter provocado perturbação, movimentos, afetos, por outro, a responsabilidade e o comprometimento com os profissionais participantes da pesquisa. Pois sim, naquele instante tive uma forte sensação de que nada havia terminado, de que o processo é longo e se abre para novas conexões.

Voltando à escola para ver o que a professora queria corrigir ou completar em seu questionário, surpreendem-nos seus questionamentos: "O que essa pesquisa pode contribuir para os professores de filosofia de Aracruz? Para o ensino de filosofia em nossas escolas". E completa: "Estou à disposição para fazer minhas aulas melhores". Tal atitude nos mostrou que, conhecendo, conversando e nos encontrando com os professores e as professoras de filosofia no município de Aracruz, podemos ver como os participantes da pesquisa demonstraram entusiasmo, desejo de, de uma forma ou de outra, encontrar meios para uma formação docente significativa, que pudesse contribuir com os processos de ensinar e aprender. A título de exemplo, tal tentativa e necessidade foi confirmada por dois professores que se inscreveram no processo seletivo de mestrado em Ensino na Educação Básica do CEUNES no ano seguinte à pesquisa (2015), os quais relataram que a pesquisa, a presença do pesquisador, as conversas, os encontros, a alegria, o entusiasmo provocaram desejos à

\footnotetext{
${ }^{6}$ Essa narrativa está descrita num aspecto coloquial para manter a autenticidade do momento com a professora e o registro no diário de campo (2015).
} 
mobilização de sua própria prática. Registramos, aqui, com alegria, quem um deles foi aprovado e defendeu dissertação no Programa.

\section{Considerações sem-fim: uma experiência de pesquisa como transformação}

Pesquisar a presença da filosofia na prática educacional e considerar outros modos de pensar o sentido do seu ensino nos permitiu viver tensões inevitáveis, potencialidades e fraquezas. Abrir-se à experiência, à criação, às conexões, às linhas de fuga, ao pensamento, ao encontro, tornou-se imprescindível à produção dessa pesquisa: contínuo fluxo de sentidos que atravessou as linhas molares com intensidades moleculares, engendrando devires, pensamentos abertos e rizomáticos. E assim, Deleuze, Kohan e Gallo nos convidaram e nos desafiaram.

Viver essa nova experiência, por intencionalidades e desejos próprios a encontrar-se com o que estava exterior a nós foi um movimento de escuta, de paciência, de cuidado, de risco e, acima de tudo, de produtividade e liberdade. A filosofia dá lugar a um modo de vida, faz sentir e provocar, incomoda e faz ocupar-nos de nós mesmos e dos outros. Assim, essa experiência nos fez sentir o prazer de pesquisar.

Nesse momento as coisas e as pessoas já não poderiam ser mais da mesma maneira como no início, elas saíram do lugar e arriscaram-se nos espaços nômades. Somos outros, outras pessoas: criamos, inventamos, experimentamos, agenciamos; com erros, sim, mas nas condições de inquietações, de desejos, de afetos, de abertura às possibilidades do encontro. Se uma experiência é o que pode nos afetar, deslocar de sentido e mudar a vida de uma pessoa ou de muitas pessoas, esta experiência provocou encontros alegres, potências de pensamentos, invenções e desejos no coletivo fluxo de agir.

É extraordinário o encontro e que encontros! Quantos acontecimentos imprevisíveis! Quantos jeitos próprios de pensar e de fazer, quantas tentativas, deslizes, invenções, tensões e alegrias que a cada dia aumentava nossa potência de pensar e de agir. A cada dia com a pesquisa íamos nos sentindo mais afetados pelos participantes que, também, nos provocavam, nos 
desafiavam a pensar de outro modo e, sobretudo, a fazer dessa pesquisa um devir, uma potência nômade, tipo uma dissertação-acontecimento. As linhas traçadas, quebradas, molares e moleculares se encontravam e se desencontravam, se misturavam no mesmo "lugar", o que nos levou a produzir linhas de fuga, encontrar uma possibilidade de produzir algo real, criar vida ao ensino de filosofia.

Nas pesquisas nem sempre encontramos ou produzimos apenas experiências potentes, alegrias e satisfações; e assim, os mapas dessa pesquisa apresentam potencialidades, perspectivas, criações, invenções, conhecimentos, mas também, tensões, desafios, fragilidades, dificuldades, impasses, lacunas e os possíveis imprevistos do cotidiano. De um lado, pensamentos, criações, linhas de fuga, a liberdade e a vida; de outro, o controle, a disciplina, a objetividade, a memorização, as insatisfações, a ausência. Aí nos situamos, nos problematizamos e buscamos sair mais fortes, mais livres.

Com a inspiração cartográfica, nos propusemos acompanhar processos e movimentos filosóficos ao invés de reconhecer, regular ou julgar. Assim, trazemos com alegria as linhas emaranhadas, os movimentos que foram cartografados entre e com os participantes da pesquisa. Entre tantas idas e vindas, as rupturas e os demais princípios rizomáticos se fazem presentes nessa experiência-pesquisa.

O sentido dessa experiência está aberto, nos atravessa e nos toca. Não pretendemos sair do meio e dar um ponto final. E assim, não pretendemos fazer dessa experiência uma árvore com suas raízes fixas, mas seguir seus rizomas, sem esquecer que há nós arborescentes nos rizomas, mas também forças rizomáticas nas raízes.

Se para a filosofia há uma necessidade de educarmos no e pelo o pensamento, que cheguemos à ousadia de experimentar o pensar e o inventar, assim como o desafio proposto pelos nossos pensadores-intercessores, nos perguntamos: o que podemos, então, ousar inventar com essa experiência, com esse movimento de prazer e de alegria com os participantes da pesquisa? Que outros encontros e acontecimentos? Quiçá novas experiências e novos agenciamentos com invenções e sentidos. 
Que possamos, então, criar, tecer linhas de fuga. Criar é aventurar-se, é abrir-se para novos agenciamentos, é sair do lugar próprio, é experimentar as linhas movediças da nossa vida e permitir que outros espaços se abram e outras experiências aconteçam: que deixemos em aberto outras conexões, outros fluxos, permitindo que essa história possa continuar.

Ora, somos nós professores e professoras que somos desafiados a revitalizar e reinventar uma prática diferente, arriscar, disponibilizar espaço para o pensamento, para novos fazeres, novas práticas, novas invenções e conexões. Ora, temos pensado e inventado nossas práticas/experiências? Ocupamo-nos de nosso pensamento? Temos propiciado inquietações e desejos? O que ensinamos quando a proposta é ensinar a pensar? Como nós mesmos nos sentimos professores e professoras? Que continuemos o processo, que encontremos aspirações para pensar o ensino em nossas escolas públicas, inventando, incomodando, deslocando pensamentos e produzindo conceitos em nossos encontros-devires. O pensamento é experimentação para Deleuze. Que experimentamos, pois, a potência do pensamento. Que encontremos forças para desdobrar potências impensadas em nossas práticas. Assim podemos, também, terminar: o que pode uma pesquisa?

Ora, como a vespa e a orquídea fazem rizoma, façamos rizomas em nossas vidas, entre escolas e estudantes, entre escola e universidade, entre ensino e pesquisa. Encerramos com um pensamento de Deleuze e Guattari (1995, p. 25): "muitas pessoas têm uma árvore plantada na cabeça, mas o próprio cérebro é muito mais uma erva do que uma árvore". Sigamos, pois, os rizomas...

\section{Referências}

BARROS, L. P.; KASTRUP, V. Cartografar é acompanhar processos. In: PASSOS, E.; KASTRUP, V.; ESCÓSSIA, L. de (Orgs.). Pistas do método cartográfico: pesquisa-intervenção e produção de subjetividade. Porto Alegre: Sulina, 2012.

CERTEAU, M. de. A invenção do cotidiano: artes de fazer. Petrópolis: Vozes, 1994. 
DELEUZE, G. O abecedário de Gilles Deleuze. 1994. [Transcrição integral do vídeo, para fins exclusivamente didáticos. 1988 (vídeo), 1994 (transcrição). Mimeo, s.d. 70 p.].

Espinosa: filosofia prática. São Paulo: Escuta, 2002.

DELEUZE G.; GUATTARI, F. Mil Platôs: capitalismo e esquizofrenia. Vol. 1. São Paulo: 34, 1995.

DELEUZE, G.; PARNET, C. Diálogos. Trad. Eloísa Araújo Ribeiro. São Paulo: Escuta, 1998.

FERRAÇO, C. E. Pesquisa com o cotidiano. Educação e Sociedade, Campinas, vol. 28, n. 98, p. 73-95, jan./abr. 2007.

FERRAÇO, C. E,; CARVALHO, J. M. Currículo, cotidiano e conversações. Revista e-curriculum, São Paulo, v.8 n.2, 2012. ISSN: 1809-3876. Disponível em: <http://revistas.pucsp.br/index.php/curriculum>. Acesso em: 05 Jun. 2020.

FOUCAULT, M. História da sexualidade II: o uso dos prazeres. Tradução de Maria Thereza de C. Albuquerque. 8. ed. Rio de Janeiro: Graal, 1998.

GALLO, S. A filosofia e seu ensino: conceito e transversalidade. ETHICA, Rio de Janeiro, v.13, n.1, p. 17-35, 2006.

. Metodologia do ensino de filosofia: uma didática para o ensino médio. Campinas, SP: Papirus, 2012.

GARCIA, R. L. A difícil arte/ciência de pesquisar com o cotidiano. In: GARCIA, R. L. (Org.). Método, métodos, contramétodo. São Paulo: Cortez, 2003.

KOHAN, W. O. Fundamentos à prática da filosofia na escola pública. In: Kohan, W. O.; LEAL, B.; RIBEIRO, A. (Orgs.). Filosofia na escola pública. 2. ed. Petrópolis, RJ: Vozes, 2000.

. Infância: entre educação e filosofia. Belo Horizonte: Autêntica, 2005.

. Infância, estrangeiridade e ignorância. Belo Horizonte: Autêntica, 2007.

LARROSA, Jorge. Notas sobre a experiência e o saber de experiência. Revista Brasileira de Educação, Rio de Janeiro, n. 19, p. 20-28, jan./abr. 2002. Disponível em: <http://www.redalyc.org/articulo.oa?id=27501903>. Acesso em: 05 Jun. 2020.

MACHADO, R. Deleuze, a arte e a filosofia. Rio de Janeiro: Zahar, 2009.

MASSCHELEIN, J.; SIMONS, M. Sobre o preço da pesquisa pedagógica. In._. A pedagogia, a democracia, a escola. 1. ed. Belo Horizonte: Autêntica, 2014.

Em defesa da escola: uma questão pública. 2.ed. Belo Horizonte: Autêntica, 2015. 
ZEICHNER, K. M. Para além da divisão entre professor-pesquisador e pesquisador acadêmico In: GERALDI, C. M.; FIORENTINI, D. \& PEREIRA, E. M. (orgs.) Cartografia do trabalho docente: professor(a)-pesquisador(a). Campinas, Mercado de Letras?ABL, 1998.

\section{Sobre os autores}

\section{Andréa Scopel Piol}

Email: andrea.scopel.piol@gmail.com

Doutoranda em Educação (UFES). Mestra pelo Programa de Pós-graduação em Ensino na Educação Básica, UFES/CEUNES (2015). Graduada em Pedagogia. Docente da Faculdade de Ensino Superior de Linhares/ES e pedagoga da Secretaria Municipal de Aracruz/ES.

\section{Jair Miranda de Paiva}

Email: jmipaiva@gmail.com

Doutor em Educação (UFES, 2009). Pós-doutor em Educação (UERJ, 2018). Docente da Universidade Federal do Espírito Santo, campus São Mateus, Departamento de Educação e Ciências Humanas e do Programa de Pósgraduação em Ensino na Educação Básica, UFES/CEUNES. 